\title{
Comparison of surgical versus transcatheter aortic valve replacement for patients with aortic stenosis at low-intermediate risk
}

\author{
Mahin R. Khan ${ }^{1 \#, ~ W a l e e d ~ T . ~ K a y a n i 2 " ~}{ }^{2 \#}$ Malalai Manan ${ }^{3}$, Ahmad Munir ${ }^{1}$, Ihab Hamzeh ${ }^{2}$, Salim S. Virani ${ }^{2,4}$, \\ Yochai Birnbaum ${ }^{2}$, Hani Jneid ${ }^{2,4}$, Mahboob Alam ${ }^{2}$ \\ ${ }^{1}$ Division of Cardiology, McLaren-Flint/Michigan State University, Flint, MI, USA; ${ }^{2}$ Section of Cardiology, Department of Internal Medicine, \\ Baylor College of Medicine, Houston, TX, USA; ${ }^{3}$ King Edward Medical University, Lahore, Pakistan; ${ }^{4}$ Section of Cardiology, Michael E. DeBakey \\ Veterans Affairs Medical Center, Houston, TX, USA \\ Contributions: (I) Conception and design: MR Khan, WT Kayani; (II) Administrative support: M Alam; (III) Provision of study materials or patients: \\ M Manan; (IV) Collection and assembly of data: MR Khan, WT Kayani; (V) Data analysis and interpretation: MR Khan, WT Kayani, M Alam; (VI) \\ Manuscript writing: All authors; (VII) Final approval of manuscript: All authors. \\ \#These authors contributed equally to this work. \\ Correspondence to: Mahboob Alam, MD, FACC, FSCAI. Baylor Heart Clinic; 6620 Main Street, Suite 1225, Houston, TX 77030, USA. \\ Email: mahboob.alam@bcm.edu.
}

Background: To compare safety and efficacy of transcatheter aortic valve replacement (TAVR) with surgical aortic valve replacement (SAVR) in patients at low-intermediate risk, given the paucity of robust data.

Methods: We performed an aggregate data meta-analysis of 7 randomized controlled trials (RCTs) and 6,778 patients comparing TAVR with SAVR for aortic stenosis (AS) in low-intermediate risk patients (Society of Thoracic Surgeons risk-score $\leq 8 \%$ ) using the random-effects model. Primary outcome was allcause mortality at 30-day, 1-year and 2-year of follow-up. Secondary outcomes included cardiac-mortality, stroke, acute kidney injury (AKI), atrial fibrillation (AF), permanent pacemaker (PPM) implantation, majorbleeding, moderate-severe paravalvular regurgitation (PVR) and rehospitalization.

Results: All-cause mortality, cardiac-mortality and stroke were comparable between the two groups. AF was higher with SAVR at 30-day [odds ratio (OR) 0.17, 95\% confidence intervals (CI): 0.12-0.24] thorough to 2-year (OR 0.34, 95\% CI: 0.21-0.55), while PPM implantation was higher with TAVR (30-day: OR 3.31, 95\% CI: 1.64-6.66, 2-year: OR 3.17, 95\% CI: 1.02-9.86). Moderate-severe PVR was more prevalent with TAVR at all follow-ups. On inter-group comparison, patients in the low-risk group had an even lower risk of $\mathrm{AF}$, but a higher risk of PPM implantation as compared to the patients in the intermediate-risk group undergoing TAVR.

Conclusions: Compared to SAVR, TAVR had comparable all-cause mortality and stroke, lower-risk of AF, but was associated with a higher risk of PPM implantation and moderate-severe PVR in low-intermediaterisk patients. Thus, highlighting the need for longer-term follow-up before robust inferences are drawn.

Keywords: Transcatheter aortic valve replacement (TAVR); surgical aortic valve replacement (SAVR); lowintermediate risk

Submitted Oct 27, 2019. Accepted for publication Nov 27, 2019.

doi: $10.21037 / \mathrm{cdt} .2020 .02 .11$

View this article at: http://dx.doi.org/10.21037/cdt.2020.02.11 


\section{Introduction}

Transcatheter aortic valve replacement (TAVR) has become a viable treatment option for patients with aortic stenosis (AS) who are inoperable or who are at high $(>8 \%)$ or intermediate risk $(>4 \%)$ per the Society of Thoracic Surgeons-Predicted Risk of Mortality (STS-PROM) score for surgical aortic valve replacement (SAVR) $(1,2)$. However, according to Society of Thoracic Surgeons (STS) registry data, $93.9 \%$ of all patients undergoing SAVR from January 2002 to December 2010 were either low or intermediate risk (3). In the recent months, results from large scale multicenter randomized controlled trials (RCTs) comparing TAVR with SAVR in low risk have become available (4-6). As we subject TAVR therapy to lower-

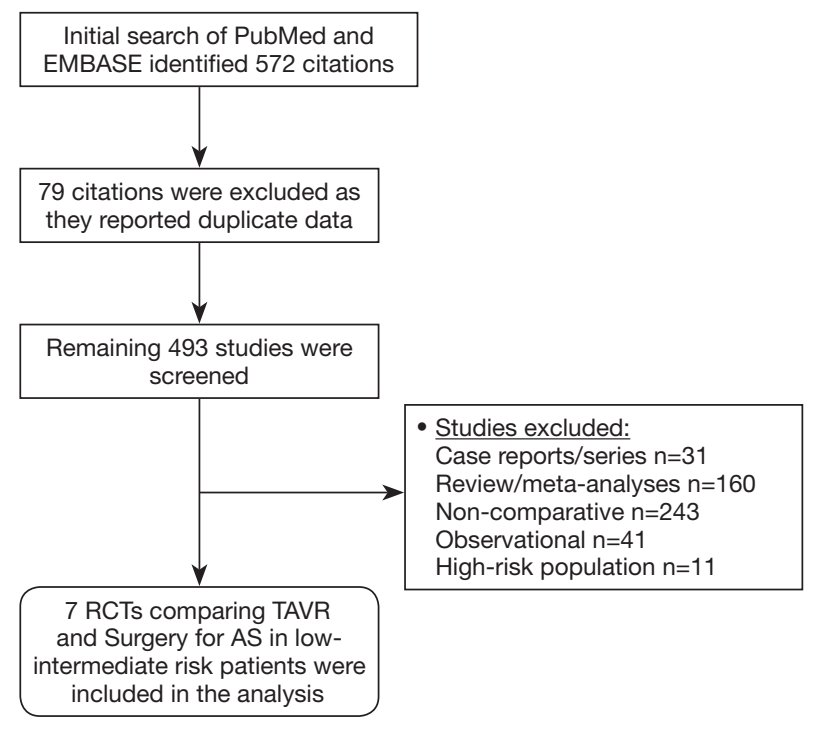

Figure 1 Literature search and methodology. risk patients, it is imperative that the risks and efficacy of TAVR is comparable to SAVR. We report a meta-analysis of RCTs comparing TAVR with SAVR for patients at low and intermediate surgical risk along with inter-group comparisons between the low- and intermediate-risk groups to improve precision of effect size of clinical outcomes and help draw robust conclusions regarding relative safety and efficacy of TAVR in this population.

\section{Methods}

A systematic, time unlimited data search of published clinical studies was performed on PubMed (MEDLINE) and EMBASE using keywords 'transcatheter aortic valve replacement', 'TAVR', 'surgical aortic valve replacement', 'SAVR', 'aortic stenosis' and 'low risk'. Our initial literature search identified 572 articles. The abstracts of relevant studies were identified and reviewed by 2 independent reviewers (MR Khan and WT Kayani). Studies included were RCTs that reported comparative outcomes between TAVR and SAVR for patients with severe AS of lowintermediate risk patients, defined by STS-PROM $\leq 8 \%$ in both the study arms. All studies that were either noncomparative, non-randomized/observational, or reported outcomes in patients with a baseline STS-PROM risk score of $>8 \%$ were excluded from our analysis (Figure 1). We also reviewed prior published meta-analyses and references of our included studies to identify studies potentially missed by our initial data search. Using the above methodology, a total of 7 RCTs (4 studies reporting outcomes of low-risk/ STS-PROM score $\leq 4 \%$ and 3 studies reporting outcomes of intermediate-risk/STS-PROM score 4-8\% patients) were included in our analysis (Table 1). Data pertaining to baseline demographics and outcomes were extracted by 2

Table 1 Summary of the studies included in the meta-analyses

\begin{tabular}{|c|c|c|c|c|c|c|c|}
\hline Publication year & Study name & Author & STS risk group & TAVR (n) & SAVR (n) & Trans-femoral & Mean follow-up \\
\hline 2019 & NOTION & Thyregod et al. & Low & 145 & 135 & $100 \%$ & 60 months \\
\hline 2019 & PARTNER 3 & Mack et al. & Low & 496 & 454 & $86.9 \%$ & 12 months \\
\hline 2017 & SURTAVI & Reardon et al. & Intermediate & 864 & 796 & $93.6 \%$ & 24 months \\
\hline 2016 & PARTNER 2 & Leon et al. & Intermediate & 1,011 & 1,021 & $76.7 \%$ & 24 months \\
\hline 2012 & STACCATO & Nielsen et al. & Low & 34 & 36 & $0 \%$ & 1 month \\
\hline
\end{tabular}

SAVR, surgical aortic valve replacement; STS, Society of Thoracic Surgeons; TAVR, transcatheter aortic valve replacement. 


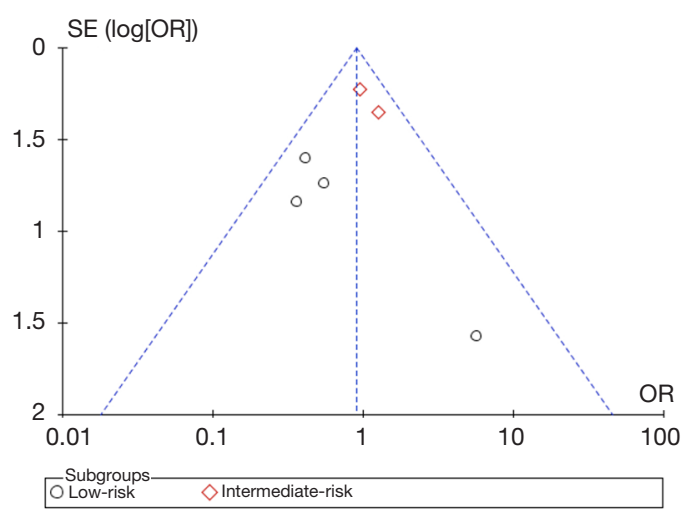

Figure 2 Funnel plot for publication bias.

reviewers (MR Khan and M Manan). Quality analysis of the included studies was performed using Cochrane's Risk of Bias Tool (Figure S1).

We performed aggregate data meta-analyses of clinical outcomes. Our primary outcome was all-cause mortality at short (30-day), intermediate (1-year) and long-term ( $\geq 2$-year) follow-up. The secondary outcomes at 30 day of follow up were cardiac mortality, stroke, major bleeding, acute kidney injury (AKI), atrial fibrillation $(\mathrm{AF})$, permanent pacemaker (PPM) implantation, major vascular complications and moderate-severe paravalvular regurgitation (PVR). The secondary outcomes at 1-year and $\geq 2$-year of follow-up were cardiac mortality, stroke, AF, PPM implantation, all-cause re-hospitalization and moderate-severe PVR. We used the studies' defined endpoints for our analyses. An inter-group comparison analysis between low and intermediate-risk groups was also performed for all outcomes. We performed sensitivity analyses after exclusion of STACCATO trial (7) (since there were no transfemoral cases in the trial and hence it is not reflective of current practice) and comparison of TAVR with SAVR with trials utilizing SAPIEN-3 or EVOLUT $\mathrm{R} / \mathrm{PRO}$ valves that currently are most commonly used. $\mathrm{P}$ value of $<0.05$ was considered statistically significant for an intergroup difference between low and intermediate groups for the given outcome. Continuous variables (described as mean \pm standard deviation) were compared using the 2 -tailed student $t$-test while the categorical variables (described as percentages) were compared using chi-square test with Yates' correction, where applicable. The outcomes were reported as odds ratio (OR) and 95\% confidence intervals (CI) and were computed using Mantel-Haenszel random effects model. Measures of heterogeneity including
Cochran's Q statistic and $\mathrm{I}^{2}$ were also computed. The analysis of baseline data was performed using the Statistical Package for Social Scientists (IBM Inc., version 19.0), while the meta-analyses were performed using Review Manager (version 5.0, Cochrane Collaboration).

\section{Results}

Our meta-analyses included 7 RCTs and a total of 6,778 patients at low-intermediate risk (STS-PROM $\leq 8 \%$ ). A funnel plot was generated that did not indicate a publication bias (Figure 2). Patients in the TAVR and SAVR groups had comparable baseline demographic and echocardiographic variables (Table S1). In total, $88 \%$ of the patients in the TAVR arm underwent the procedure through transfemoral access. The primary outcome of all-cause mortality was comparable at 30-day (TAVR 2.1\%, SAVR 2.4\%; OR 0.88, 95\% CI: $0.60-1.31$ ), 1-year (TAVR $6.5 \%$, SAVR 7.1\%; OR 0.93, 95\% CI: 0.76-1.13) and 2-year (TAVR 12.5\%, SAVR 13.4\%; OR 0.91, 95\% CI: 0.75-1.10) follow-up in both treatment arms (Figure 3 and Tables 2,3,4). A similar trend i.e., no comparable difference in stroke and cardiac mortality was found in the two groups at all follow-up intervals (Tables 2,3,4). At 30-day of follow-up, TAVR had significantly lower rates of AF (TAVR 9.3\%, SAVR 34.8\%; OR $0.17,95 \%$ CI: $0.12-0.24$ ), AKI (OR 0.37, 95\% CI: $0.25-0.54$ ) and major bleeding (OR 0.32, 95\% CI: $0.11-$ 0.91) but higher rates of PPM implantation (TAVR 15.8\%, SAVR 5.9\%; OR 3.31, 95\% CI: 1.64-6.66), major vascular complications (OR 2.09, 95\% CI: 1.18-3.71) and moderatesevere PVR (TAVR 2.2\%, SAVR 0.3\%; OR 5.97, 95\% CI: 2.67-13.34) as compared to SAVR (Table 2 and Figure 4).

The patients in low-risk cohort had a statistically significant benefit of even lower incidence of AF from TAVR (OR 0.20, 95\% CI: 0.12-0.33) as compared to the patients in intermediate risk cohort (OR 0.42, 95\% CI: $0.25-0.70)(\mathrm{P}=0.04)$. This advantage of TAVR over surgery in the incidence of $\mathrm{AF}$ in low-risk compared to intermediate-risk patients continued at 1-year and 2-year of follow up (Tables 3,4). On the contrary, TAVR had increased rates of PPM implantations at 1-year (TAVR 13.7\%, SAVR 6.9\%; OR 2.88, 95\% CI: 1.23-6.72) and 2-year (TAVR $16.8 \%$, SAVR 9.3\%; OR 3.17, 95\% CI: 1.02-9.86) of follow-up. Patients at low-risk were more likely to get a PPM (OR 8.33, 95\% CI: 4.04-17.20) than the patients than patients at an intermediate-risk (OR 2.00, 95\% CI: 0.72 5.55) $(\mathrm{P}=0.03)$. TAVR was also associated with a higher incidence of moderate-severe PVR at 1-year (OR 5.69, 95\% 


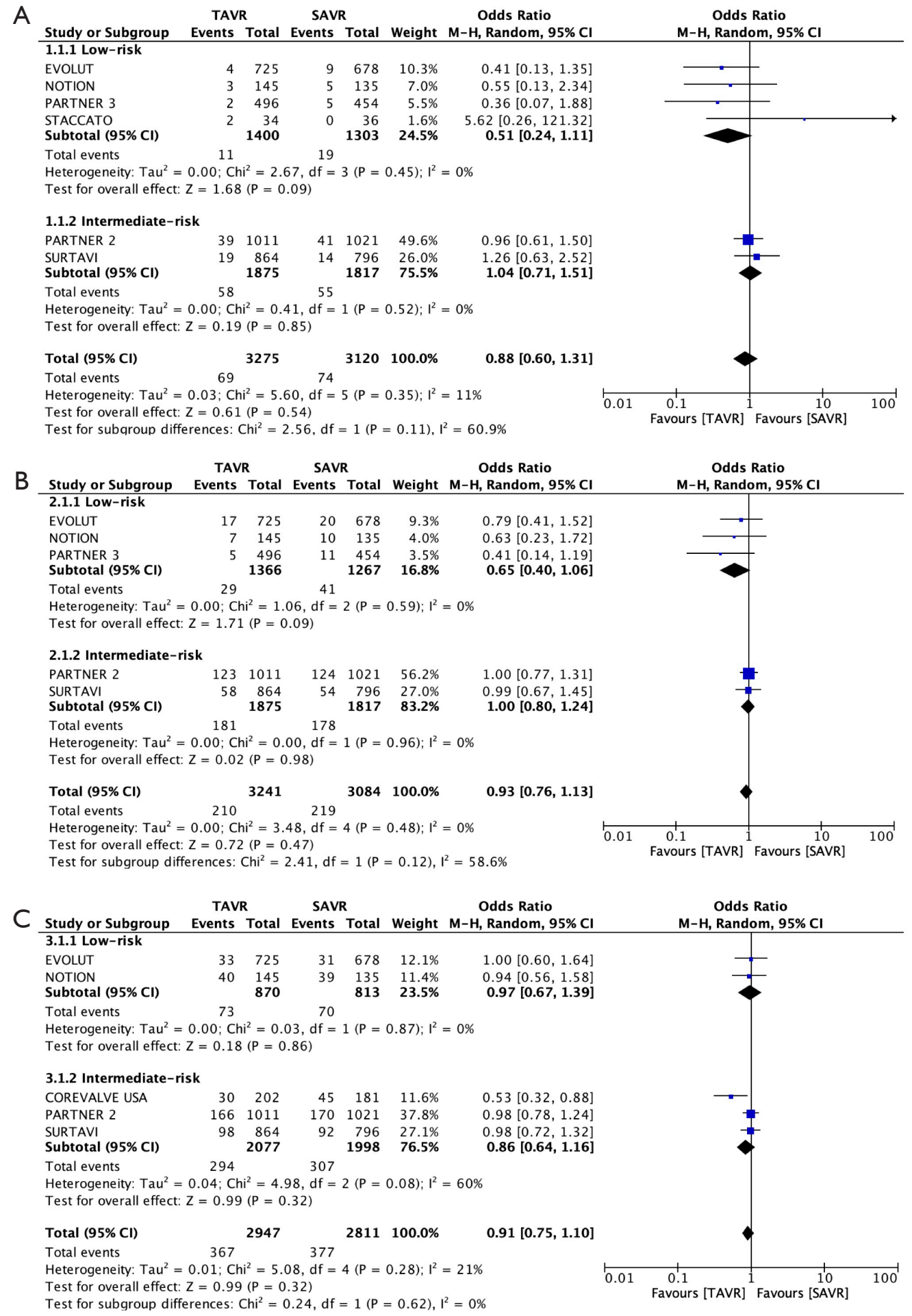

Figure 3 Forest plots of all-cause mortality at (A) 30-day, (B) 1-year and (C) $\geq 2$-year. 


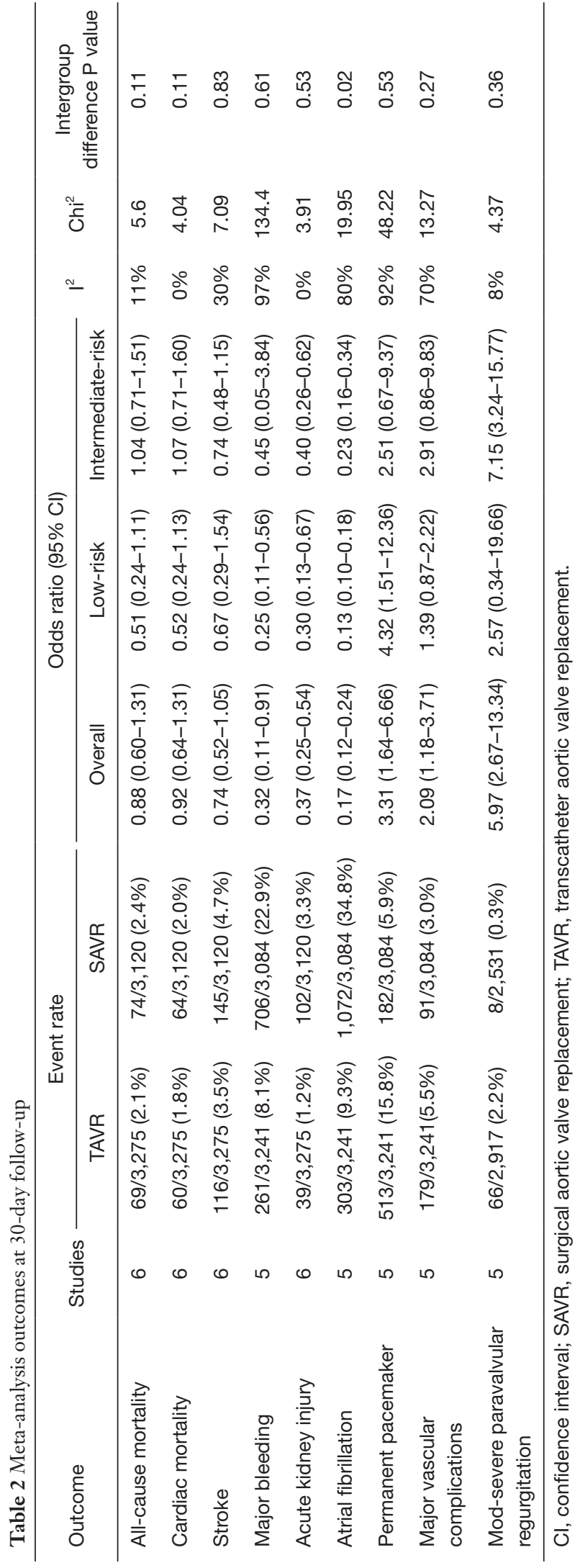

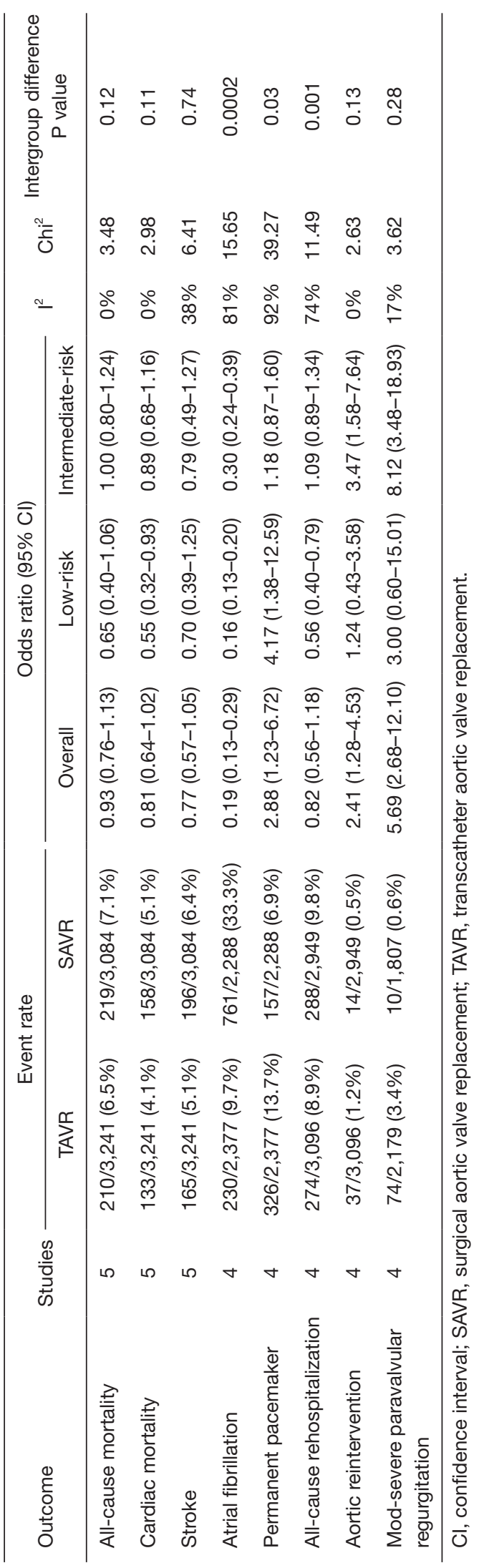




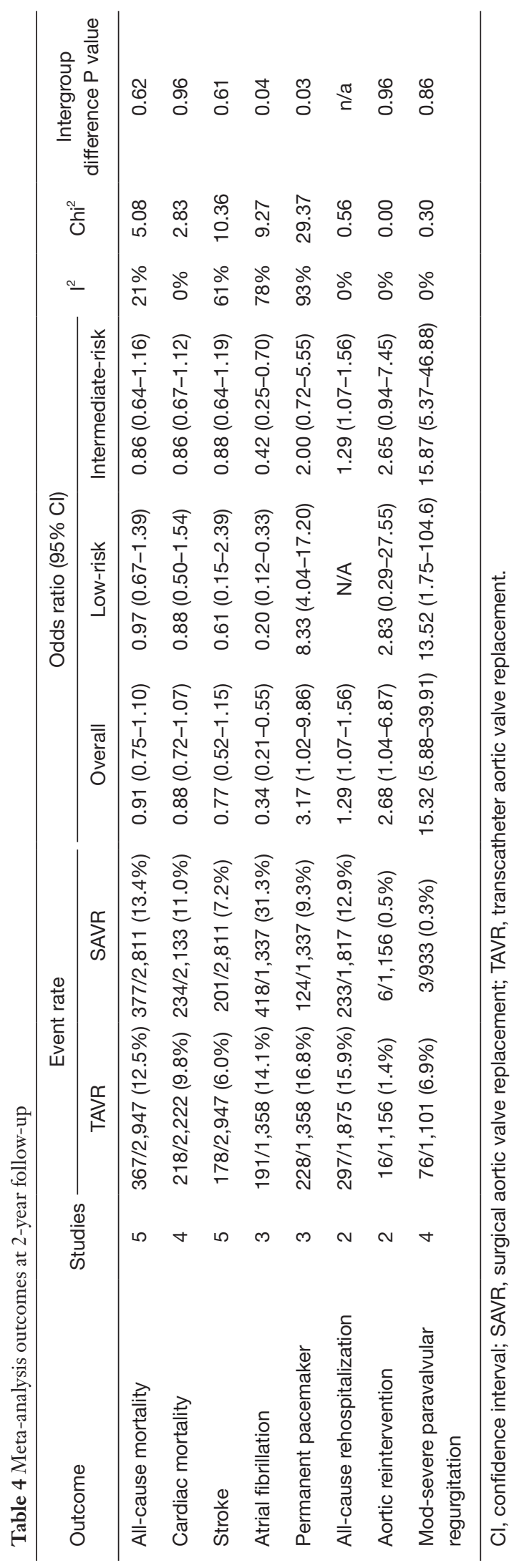

CI: 2.68-12.1) and 2-year of follow-up (OR 15.32, 95\% CI: 5.88-39.91), the wide confidence interval being secondary likely to a low event rate, specifically with SAVR $(0.6 \%$ and $0.3 \%$ at 1 and 2 -year respectively).

All-cause rehospitalization rates were lower with TAVR in low-risk patients as compared to surgery (OR 0.56, 95\% CI: $0.40-0.79)$ but not in the patients at intermediate-risk (OR 1.09, 95\% CI: 0.89-1.34) at 1 year of follow-up. Data at 2-year of follow-up showed increased rehospitalization with TAVR as compared to surgery (OR 1.29, 95\% CI: $1.07-1.56)$. It is however noteworthy that none of the included trials on low-risk patients presented data on rehospitalization at 2-year of follow-up and the calculated data are from the analysis of trials on intermediate risk patients (Table 4).

Sensitivity analyses with the exclusion of STACCATO trial (Table S2) did not change the accrual mortality with TAVR $(2.1 \%)$ or SAVR (2.4\%), however the odds of mortality with TAVR were better as compared to SAVR at 30-day follow-up in the low-risk subset (OR 0.44, 95\% CI: 0.20-0.97). The comparison of TAVR done with either EVOLUT R, EVOLUT PRO or SAPIEN 3 with SAVR at 1-year follow-up included 2 studies (Table S3) and showed no difference in all-cause mortality (OR 0.65, 95\% CI: $0.37-1.17$ ) and cardiac mortality (OR $0.55,95 \%$ CI: 0.29 1.02) between TAVR and SAVR, significantly less incidence of AF (OR 0.15, 95\% CI: 0.11-0.21) and an increased risk of pacemaker placement (OR 2.23, 95\% CI: 0.94-5.31) with TAVR. However, there was no statistically significant difference between TAVR and SAVR in terms of moderatesevere PVR (OR 3.00, 95\% CI: 0.60-15.01) (Table S3).

\section{Discussion}

In this meta-analysis comprising 6,778 randomized low or intermediate risk patients from with severe AS undergoing TAVR vs SAVR, we found no significant difference in shortand long-term all-cause mortality, cardiovascular mortality and stroke. Patients undergoing TAVR overall had a significantly lower incidence of AF and AKI, while repeat hospitalization was lower with TAVR in low-risk subgroup at 1-year of follow-up. A higher incidence of moderatesevere PVR and PPM implantation was noted in the TAVR group. We have included all landmark trials in this cohort and the findings are important as only RCTs were included in our analysis.

Since showing a remarkable reduction in mortality in patients at a prohibitive risk of surgery with severe 
A

TAVR SAVR Odds Ratio

\begin{tabular}{|c|c|c|c|c|c|c|}
\hline \multirow{3}{*}{$\begin{array}{l}\text { Study or Subgroup } \\
1.5 .1 \text { Low-risk }\end{array}$} & & & \multirow[b]{2}{*}{ Weight } & \multirow{2}{*}{$\begin{array}{l}\text { Odds Ratio } \\
\text { M-H, Random, } 95 \% \mathrm{CI}\end{array}$} \\
\hline & Events & Total & Events & Total & & \\
\hline & & & & & & \\
\hline EVOLUT & 7 & 725 & 19 & 678 & $18.6 \%$ & $0.34[0.14,0.81]$ \\
\hline NOTION & 1 & 145 & 9 & 135 & $3.3 \%$ & $0.10[0.01,0.78]$ \\
\hline PARTNER 3 & 2 & 496 & 8 & 454 & $5.9 \%$ & $0.23[0.05,1.07]$ \\
\hline STACCATO & 1 & 34 & 0 & 36 & $1.4 \%$ & $3.27[0.13,83.03]$ \\
\hline Subtotal $(95 \% \mathrm{Cl})$ & & 1400 & & 1303 & $29.1 \%$ & $0.30[0.13,0.67]$ \\
\hline Total events & 11 & & 36 & & & \\
\hline $\begin{array}{l}\text { Heterogeneity: Tau } \\
\text { Test for overall effe }\end{array}$ & $\begin{array}{l}0 ; C h \\
2.94\end{array}$ & $1^{2}=3$ & df & $3(P=$ & 33); & \\
\hline
\end{tabular}

1.5.2 Intermediate-risk

PARTNER 2
SURTAVI

SURTAVI
Subtotal $(95 \% \mathrm{CI})$

Total events

$\begin{array}{lllll}13 & 1011 & 31 & 1021 & 33.2 \%\end{array}$

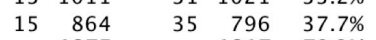

$0.42[0.22,0.80]$

$0.38[0.21,0.71]$

Heterogeneity: $\mathrm{Tau}^{2}=0.00 ; \mathrm{Chi}^{2}=0.03, \mathrm{df}=1(\mathrm{P}=0.86) ; \mathrm{I}^{2}=0 \%$

Test for overall effect: $Z=4.03(P<0.0001)$

$\begin{array}{lllll}\text { Total }(95 \% \mathrm{Cl}) & 3275 & 3120 & 100.0 \% & 0.37\end{array}[0.25,0.54]$

Total events $\quad 39 \quad 102$

Heterogeneity: $\mathrm{Tau}^{2}=0.00 ; \mathrm{Chi}^{2}=3.91, \mathrm{df}=5(\mathrm{P}=0.56) ; \mathrm{I}^{2}=0 \%$

Test for overall effect: $Z=5.21(P<0.00001)$

Test for subgroup differences: $\mathrm{Chi}^{2}=0.39, \mathrm{df}=1(\mathrm{P}=0.53), \mathrm{I}^{2}=0 \%$

$0.40[0.26,0.62]$

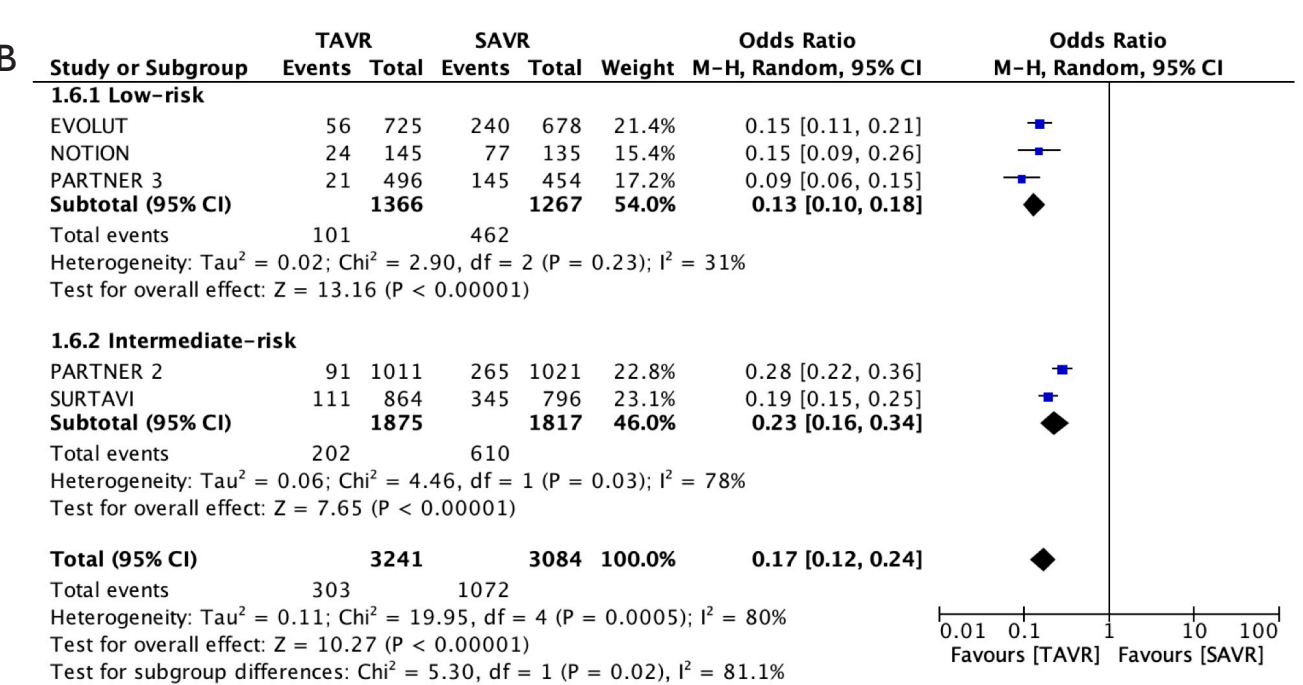

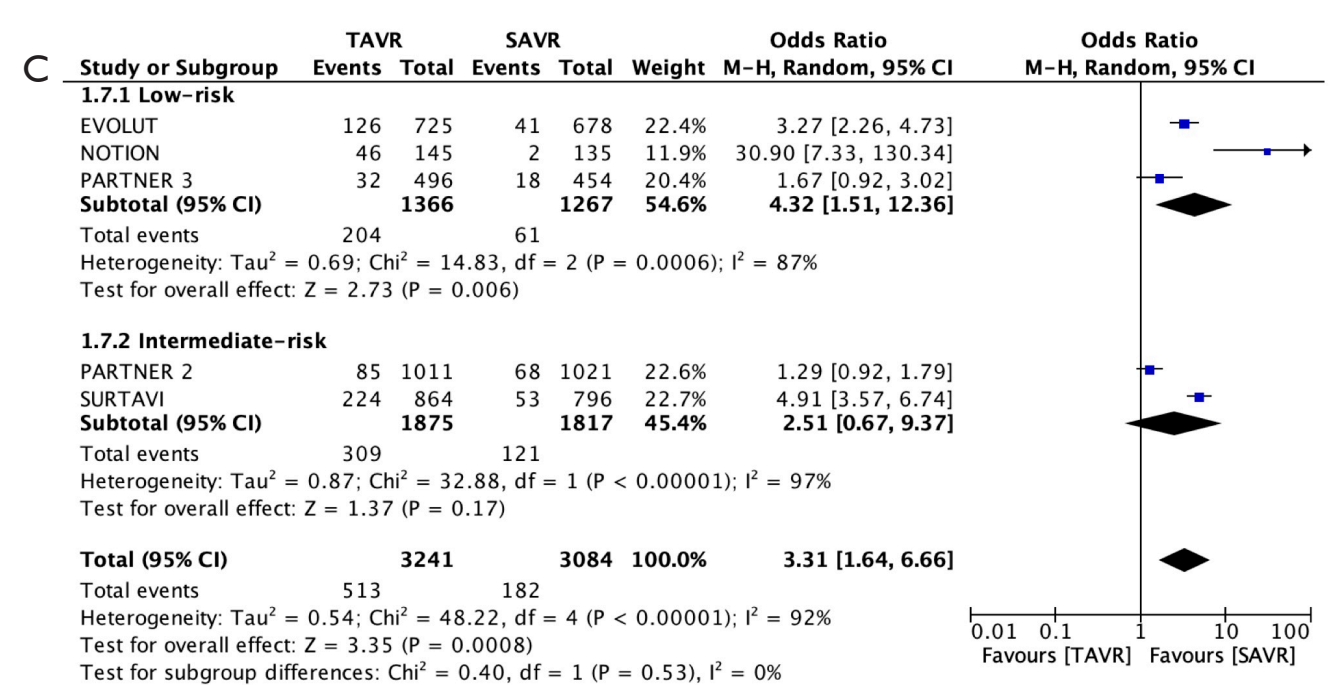

Figure 4 Forest plot of (A) Acute kidney injury, (B) atrial fibrillation and (C) permanent pacemaker implantation at 30-day. 
symptomatic AS (8), TAVR has been noted to have comparable mortality in high and intermediate risk patients $(9,10)$. In our analysis of all RCTs with low-intermediate risk, no significant difference in 30-day, 1 year or 2-year all-cause and cardiac mortality were seen in patients undergoing TAVR compared to SAVR with a trend favoring TAVR. Further subgroup analysis of patients at a lower surgical risk showed a more favorable trend favoring TAVR, however it did not reach statistical significance. However, with sensitivity analyses excluding STACCATO trial (7), TAVR had a favorable all-cause mortality profile in the lowrisk subgroup at 1 -year follow up. These findings are of importance given low heterogeneity (Figure 3) especially as the indications of TAVR are expanded to lower risk populations.

A comparable incidence of stroke between TAVR and SAVR was noted in low and intermediate risk subgroups in our analysis. This finding reflects an important advancement in the transcatheter valve prostheses safety as the earlier trials reported a higher incidence of strokes with TAVR compared to SAVR e.g., neurologic events (stroke and transient ischemic attack) were greater in the TAVR group at one year $(8.3 \%$ vs. $4.3 \%, \mathrm{P}=0.04)$ in PARTNER 1 trial (10). Whereas the lower risk populations enrolled in the trials was definitely a factor, the improvement in valve technology, lower device profile, greater use of transfemoral approach and improved operator expertise all appear to have played a part in improving this important safety outcome. However, given the relatively low use or exclusion of embolic protection devices in the enrolled trials, robust conclusion regarding their use cannot be drawn. As TAVR is offered to even lower risk patients, it is imperative to further improve our clinical outcomes. Since stroke remains a highly morbid and potentially fatal complication, the decreased absolute risk of stroke with TAVR over time is an encouraging finding, however.

A significant reduction in major bleeding, AF and AKI were noted in favor of TAVR in our analysis. These findings are important as all have been independently shown to worsen morbidity and mortality $(11,12)$. Similarly, a lower incidence of rehospitalization was noted favoring TAVR at 12 months in the low-risk population, with no significant difference in 12 -month rehospitalization in the intermediate-risk population $(\mathrm{P}=0.001)$. At 24 months however, we noted increased rehospitalization with TAVR (15.9\%) as compared to SAVR (12.9\%) in intermediate-risk patients, with no available data for low-risk patients.

A higher incidence of PPM implantation was noted with TAVR compared to SAVR at all stages of follow up. Interestingly, TAVR was associated with a significantly higher odds of PPM implantation in patients in the lowrisk group as compared to the intermediate group at 1 and 2-year $(\mathrm{P}=0.03)$ follow up. Although a direct comparison of prostheses has not been done, it is well established that selfexpanding prostheses (EVOLUT and CORE VALVE) have a higher risk of PPM implantation compared to balloon expandable SAPIEN valves likely due to the continuous radial force of the self-expanding prostheses and resultant compression of the atrio-ventricular node and the left bundle branch (13). Size, structural characteristics of the valve like the use of an external fabric cuff in the SAPIEN 3 valve and the depth of valve deployment contribute to the need of a PPM and conduction abnormalities (14). The PARTNER 3 trial utilized a higher implantation depth of SAPIEN 3 prosthesis and reported no significant difference in new pacemaker implantation rates among patients undergoing SAVR vs. TAVR (4). The relatively higher risk of PPM implantation in our study in the low-risk subgroup is likely secondary to the use of self-expanding prosthesis in a relatively greater percentage of patients in the former as compared to the intermediate-risk subgroup.

Although new PPM insertion post TAVR has not been definitely showed to impact short term mortality it seems to have unfavorable effects on left ventricular function (15-17) with the need for pacing increasing the risk of heart failure and late-mortality (18). The higher risk of PPM at implantation with TAVR in low-intermediate risk patients is an important finding especially as TAVR indication if expanded to younger, lower risk populations who are more likely to have a higher life expectancy, highlighting the need for longer-term follow-up in this population.

TAVR was associated with a higher risk of moderatesevere PVR in our analyses. Similarly, the risk of moderatesevere PVR was higher with TAVR as per the EVOLUT trial (19) but similar to SAVR per data from PARTNER-3 trial (4), likely owing to the use of self-expanding bioprosthesis in the EVOLUT study and the use of SAPIEN 3 valve in PARTNER 3. Five-year follow-up data from PARTNER-1 trial reported comparable mortality between TAVR and SAVR, however there was a higher PVR with TAVR and a higher mortality associated with the presence of PVR with TAVR $(20,21)$. However, on comparing TAVR with EVOLUT R/PRO and SAPIEN 3 versus SAVR, we did not find a statistically significant difference in moderatesevere PVR between the two modalities at 1-year, indicating that further evolution in valve engineering and technique 
might narrow down the difference in PVR between the two modalities. Long-term implications of the increased incidence of PVR with TAVR remain to be seen before robust conclusions can be drawn regarding the durability of the prosthesis in low-intermediate risk patients.

Taking real world registry data from Germanythe country with highest penetration rate of TAVR, the German Aortic Valve Registry recently reported on clinical management of severe AS in 20,549 patients at low surgical risk. Adjusted analysis demonstrated that TAVR (mean age 78.9 years) was associated with improved 30-day survival (98.3\% vs. 97.0\%; $\mathrm{P}=0.001$ ) and similar 12 -month survival (90.4\% vs. 91.2\%; $\mathrm{P}=0.368$ ) rates compared with SAVR (mean age 67.5 years). TAVR was rarely performed $(<5 \%)$ in patients under 70 years old but was the predominant treatment in patients older than 75 at low surgical risk $(4,760 / 8,439,56 \%)(22)$.

Our analysis has limitations. First, a meta-analysis is always limited by the quality of enrolled studies. Second, there always exist differences in the enrolled patients among different trials due to varying inclusion criteria. Third, significant heterogeneity was seen in some secondary outcomes e.g., AF and PPM implantation even while using random effects model. However, to mitigate this, we only included RCTs in our analysis and believe that our results were robust for most of our outcomes and specifically, the primary outcome of mortality. As we used the studies' defined endpoints for our analyses, the definitions of clinical outcomes may be slightly different across studies, however, we tried to standardize outcomes wherever possible. The choice of access route might have affected TAVR related outcomes. Even though $88 \%$ of the patients in our analysis underwent TAVR through transfemoral access, alternate access like transapical approach has been associated with worse clinical outcomes (23). Also, the number of patientyear follow-up in our study is limited due to lack of availability of longer-term follow-up in the available data.

\section{Conclusions}

Although the data regarding TAVR in intermediate and low risk populations is encouraging, the question remains regarding the longevity and performance of TAVR prostheses in younger patients with a longer projected life expectancy than higher risk patients. A potential approach could be initially selecting "older" low-risk patients for TAVR till more data on the long-term performance of the TAVR prostheses is available.

\section{Acknowledgments}

Funding: None.

\section{Footnote}

Conflicts of Interest: All authors have completed the ICMJE uniform disclosure form (available at http://dx.doi. org/10.21037/cdt.2020.02.11). SSV reports grants from Department of Veterans Affairs, World Heart Federation, outside the submitted work; and Honorarium: American College of Cardiology (Associate Editor for Innovations, acc.org) Steering Committee member: Patient and Provider Assessment of Lipid Management (PALM) registry at the Duke Clinical Research Institute (no financial remuneration). The other authors have no conflicts of interest to declare.

Ethical Statement: The authors are accountable for all aspects of the work in ensuring that questions related to the accuracy or integrity of any part of the work are appropriately investigated and resolved.

Open Access Statement: This is an Open Access article distributed in accordance with the Creative Commons Attribution-NonCommercial-NoDerivs 4.0 International License (CC BY-NC-ND 4.0), which permits the noncommercial replication and distribution of the article with the strict proviso that no changes or edits are made and the original work is properly cited (including links to both the formal publication through the relevant DOI and the license). See: https://creativecommons.org/licenses/by-nc-nd/4.0/.

\section{References}

1. Nishimura RA, Otto CM, Bonow RO, et al. 2014 AHA/ ACC guideline for the management of patients with valvular heart disease: a report of the American College of Cardiology/American Heart Association Task Force on Practice Guidelines. J Thorac Cardiovasc Surg 2014;148:e1-132.

2. Nishimura RA, Otto CM, Bonow RO, et al. 2017 AHA/ ACC Focused Update of the 2014 AHA/ACC Guideline for the Management of Patients With Valvular Heart Disease: A Report of the American College of Cardiology/ American Heart Association Task Force on Clinical Practice Guidelines. J Am Coll Cardiol 2017;70:252-89.

3. Thourani VH, Suri RM, Gunter RL, et al. Contemporary 
real-world outcomes of surgical aortic valve replacement in 141,905 low-risk, intermediate-risk, and high-risk patients. Ann Thorac Surg 2015;99:55-61.

4. Mack MJ, Leon MB, Thourani VH, et al. Transcatheter Aortic-Valve Replacement with a Balloon-Expandable Valve in Low-Risk Patients. N Engl J Med 2019;380:1695-705.

5. Thyregod HGH, Ihlemann N, Jørgensen TH, et al. FiveYear Clinical and Echocardiographic Outcomes from the Nordic Aortic Valve Intervention (NOTION) Randomized Clinical Trial in Lower Surgical Risk Patients. Circulation 2019. [Epub ahead of print].

6. Popma JJ, Deeb GM, Yakubov SJ, et al. Transcatheter Aortic-Valve Replacement with a Self-Expanding Valve in Low-Risk Patients. N Engl J Med 2019;380:1706-15.

7. Nielsen $\mathrm{HH}$, Klaaborg KE, Nissen H, et al. A prospective, randomised trial of transapical transcatheter aortic valve implantation vs. surgical aortic valve replacement in operable elderly patients with aortic stenosis: the STACCATO trial. EuroIntervention 2012;8:383-9.

8. Leon MB, Smith CR, Mack M, et al. Transcatheter aortic-valve implantation for aortic stenosis in patients who cannot undergo surgery. N Engl J Med 2010;363:1597-607.

9. Leon MB, Smith CR, Mack MJ, et al. Transcatheter or Surgical Aortic-Valve Replacement in Intermediate-Risk Patients. N Engl J Med 2016;374:1609-20.

10. Smith CR, Leon MB, Mack MJ, et al. Transcatheter versus surgical aortic-valve replacement in high-risk patients. $\mathrm{N}$ Engl J Med 2011;364:2187-98.

11. Ram P, Mezue K, Pressman G, et al. Acute kidney injury post-transcatheter aortic valve replacement. Clin Cardiol 2017;40:1357-62.

12. Chopard R, Teiger E, Meneveau N, et al. Baseline Characteristics and Prognostic Implications of Pre-Existing and New-Onset Atrial Fibrillation After Transcatheter Aortic Valve Implantation: Results From the FRANCE-2 Registry. JACC Cardiovasc Interv 2015;8:1346-55.

13. Saji M, Murai T, Tobaru T, et al. Autopsy finding of the Sapien XT valve from a patient who died suddenly after transcatheter aortic valve replacement. Cardiovasc Interv Ther 2013;28:267-71.

14. Husser O, Pellegrini C, Kessler T, et al. Predictors of Permanent Pacemaker Implantations and New-Onset Conduction Abnormalities With the SAPIEN 3 BalloonExpandable Transcatheter Heart Valve. JACC Cardiovasc Interv 2016;9:244-54.
15. Regueiro A, Abdul-Jawad Altisent O, Del Trigo M, et al. Impact of New-Onset Left Bundle Branch Block and Periprocedural Permanent Pacemaker Implantation on Clinical Outcomes in Patients Undergoing Transcatheter Aortic Valve Replacement: A Systematic Review and MetaAnalysis. Circ Cardiovasc Interv 2016;9:e003635.

16. Urena M, Webb JG, Tamburino C, et al. Permanent pacemaker implantation after transcatheter aortic valve implantation: impact on late clinical outcomes and left ventricular function. Circulation 2014;129:1233-43.

17. Hwang IC, Hayashida K, Kim HS. Current Key Issues in Transcatheter Aortic Valve Replacement Undergoing a Paradigm Shift. Circ J 2019;83:952-62.

18. Dewland TA, Pellegrini CN, Wang Y, et al. Dual-chamber implantable cardioverter-defibrillator selection is associated with increased complication rates and mortality among patients enrolled in the NCDR implantable cardioverterdefibrillator registry. J Am Coll Cardiol 2011;58:1007-13.

19. Popma JJ, Deeb GM, Yakubov SJ, et al. Transcatheter Aortic-Valve Replacement with a Self-Expanding Valve in Low-Risk Patients. N Engl J Med 2019;380:1706-15.

20. Daubert MA, Weissman NJ, Hahn RT, et al. LongTerm Valve Performance of TAVR and SAVR: A Report From the PARTNER I Trial. JACC Cardiovasc Imaging 2016;10:15-25.

21. Mack MJ, Leon MB, Smith CR, et al. 5-year outcomes of transcatheter aortic valve replacement or surgical aortic valve replacement for high surgical risk patients with aortic stenosis (PARTNER 1): a randomised controlled trial. Lancet 2015;385:2477-84.

22. Bekeredjian R, Szabo G, Balaban U, et al. Patients at low surgical risk as defined by the Society of Thoracic Surgeons Score undergoing isolated interventional or surgical aortic valve implantation: in-hospital data and 1-year results from the German Aortic Valve Registry (GARY). Eur Heart J 2019;40:1323-30.

23. Conrotto F, D'Ascenzo F, Francesca G, et al. Impact of access on TAVI procedural and midterm follow-up: a meta-analysis of 13 studies and 10,468 patients. J Interv Cardiol 2014;27:500-8.

Cite this article as: Khan MR, Kayani WT, Manan M, Munir A, Hamzeh I, Virani SS, Birnbaum Y, Jneid H, Alam M. Comparison of surgical versus transcatheter aortic valve replacement for patients with aortic stenosis at low-intermediate risk. Cardiovasc Diagn Ther 2020;10(2):135-144. doi: 10.21037/ cdt.2020.02.11 


\begin{tabular}{|c|c|c|c|c|c|c|c|c|}
\hline ? & ? & $?$ & ? & $?$ & $?$ & $?$ & \multirow{2}{*}{\multicolumn{2}{|c|}{$\begin{array}{l}\text { Random sequence generation } \\
\text { Allocation concealment }\end{array}$}} \\
\hline ? & ? & $?$ & $?$ & $?$ & $?$ & $?$ & & \\
\hline - & - & - & - & - & - & - & \multicolumn{2}{|c|}{ Blinding of participants and personnel } \\
\hline+ & + & - & - & - & + & + & \multicolumn{2}{|c|}{ Blinding of outcome assessmen } \\
\hline+ & + & + & + & + & + & + & \multicolumn{2}{|c|}{ Incomplete outcome data } \\
\hline+ & + & + & + & + & + & + & \multicolumn{2}{|c|}{ Selective Reporting } \\
\hline$?$ & ? & $?$ & $?$ & $?$ & $?$ & - & \multicolumn{2}{|l|}{ Other bias } \\
\hline \multirow{4}{*}{ 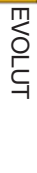 } & \multirow{4}{*}{$\begin{array}{l}\text { 号 } \\
\text { D } \\
\text { م } \\
\frac{1}{3}\end{array}$} & \multirow{4}{*}{ 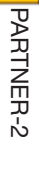 } & \multirow{4}{*}{ 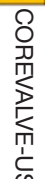 } & \multirow{4}{*}{ 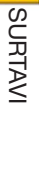 } & \multirow{4}{*}{$\begin{array}{l}\text { D } \\
\text { D } \\
\text { 至 } \\
\text { 悠 } \\
\omega \\
\omega\end{array}$} & \multirow{4}{*}{$\begin{array}{l}Z \\
\text { 음 } \\
\text { 긍 }\end{array}$} & \multicolumn{2}{|l|}{ Key } \\
\hline & & & & & & & + & Low risk of bias \\
\hline & & & & & & & - & High risk of bias \\
\hline & & & & & & & $?$ & Unclear risk of bias \\
\hline
\end{tabular}

Figure S1 Quality assessment of studies with Cochrane risk of bias tool.

Table S1 Baseline and demographic variables

\begin{tabular}{|c|c|c|c|c|c|}
\hline Variable & \multicolumn{2}{|c|}{ TAVR } & \multicolumn{2}{|c|}{ SAVR } & $P$ value \\
\hline Total & 3,477 & & 3,301 & & \\
\hline Age & 3,275 & $78.08 \pm 3.42$ & 3,120 & $78.14 \pm 3.79$ & 0.9 \\
\hline STS-PROM & 3,275 & $3.82 \pm 1.5$ & 3,120 & $3.9 \pm 1.52$ & 0.91 \\
\hline CAD & 2,371 & $1,378(58.1)$ & 2,271 & $1,317(58.0)$ & 0.95 \\
\hline Diabetes & 3,275 & 1,086 (33.2) & 3,120 & 1,022 (32.8) & 0.75 \\
\hline Hypertension & 1,734 & $1,518(87.6)$ & 1,609 & $1,381(85.8)$ & 0.15 \\
\hline Prior MI & 3,241 & 394 (12.2) & 3,084 & $355(11.5)$ & 0.44 \\
\hline COPD & 2,381 & $468(19.7)$ & 2,295 & $468(20.4)$ & 0.53 \\
\hline Cerebrovascular disease & 3,275 & $498(15.2)$ & 3,120 & $500(16.0)$ & 0.37 \\
\hline Creatinine $>2 \mathrm{mg} / \mathrm{dL}$ & 3,275 & $72(2.2)$ & 3,120 & $73(2.3)$ & 0.74 \\
\hline Atrial fibrillation & 3,238 & $785(24.2)$ & 3,084 & $787(25.5)$ & 0.24 \\
\hline Permanent pacemaker & 3,241 & $242(7.5)$ & 3,084 & $240(7.8)$ & 0.67 \\
\hline NYHA III-IV & 3,096 & $1,639(52.9)$ & 2,949 & $1,540(52.2)$ & 0.59 \\
\hline Mean AV gradient (mmHg) & 3,275 & $49.96 \pm 14.3$ & 3,120 & $46.51 \pm 8.2$ & 0.71 \\
\hline AV area $\left(\mathrm{cm}^{2}\right)$ & 3,275 & $0.76 \pm 0.06$ & 3,120 & $0.76 \pm 0.05$ & 0.81 \\
\hline
\end{tabular}

*, data presented as $\mathrm{n}(\%)$ unless otherwise specified. AV, aortic valve; CAD, coronary artery disease; COPD, chronic obstructive pulmonary disease; LVEF, left ventricular ejection fraction; MI, myocardial infarction; NYHA, New York Heart Association; PCI, percutaneous coronary intervention; SAVR, surgical aortic valve replacement; TAVR, transcatheter aortic valve replacement. 


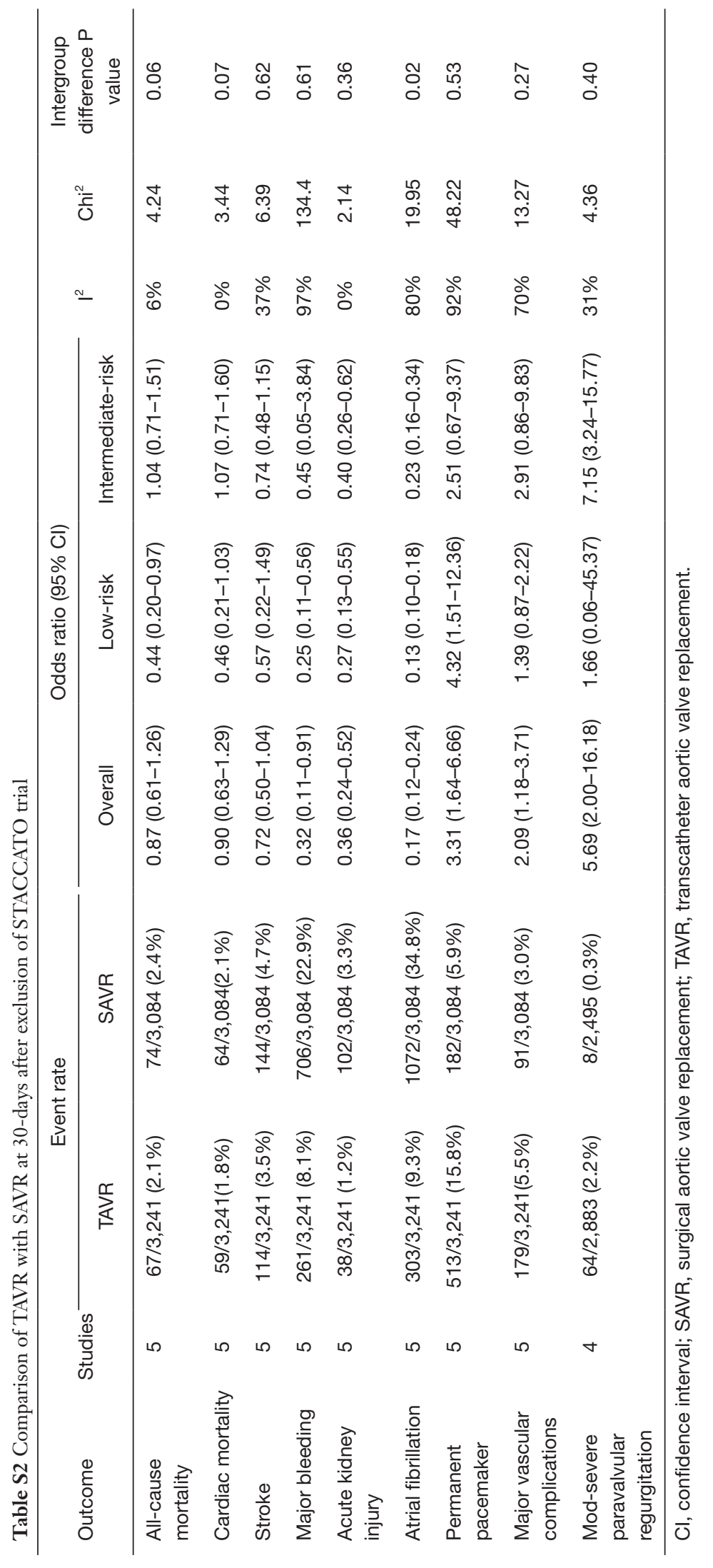


Table S3 Comparison of TAVR with SAPIEN 3 OR EVOLUT R/PRO versus SAVR at 1-year

\begin{tabular}{|c|c|c|c|c|c|c|}
\hline Outcome & Studies & \multicolumn{2}{|c|}{ Event rate } & Odds ratio $(95 \% \mathrm{Cl})$ & $1^{2}$ & $P$ value \\
\hline All-cause mortality & 2 & $22 / 1,221(1.8 \%)$ & $31 / 1,132(2.7 \%)$ & $0.65(0.37-1.17)$ & $5 \%$ & 0.15 \\
\hline Cardiac mortality & 2 & $16 / 1,221(1.3 \%)$ & $27 / 1,132(2.4 \%)$ & $0.55(0.29-1.02)$ & $0 \%$ & 0.06 \\
\hline Stroke & 2 & $36 / 1,221(2.9 \%)$ & $43 / 1,132(3.8 \%)$ & $0.67(0.28-1.62)$ & $63 \%$ & 0.37 \\
\hline Permanent pacemaker & 2 & $177 / 1,221(14.5 \%)$ & 69/1,132 (6.09\%) & $2.23(0.94-5.31)$ & $86 \%$ & 0.007 \\
\hline All-cause rehospitalization & 2 & $59 / 1,221(4.8 \%)$ & $93 / 1,132(8.2 \%)$ & $0.56(0.40-0.79)$ & $0 \%$ & 0.001 \\
\hline $\begin{array}{l}\text { Mod-severe paravalvular } \\
\text { regurgitation }\end{array}$ & 2 & $18 / 871(2.06 \%)$ & 4/708 (0.6\%) & $3.00(0.60-15.01)$ & $48 \%$ & 0.18 \\
\hline
\end{tabular}

$\mathrm{Cl}$, confidence interval; SAVR, surgical aortic valve replacement; TAVR, transcatheter aortic valve replacement. 